\title{
Life cycle thinking in sustainability assessment of bioenergy systems
}

\author{
Shabbir H. Gheewala ${ }^{1,2 *}$ \\ ${ }^{1}$ The Joint Graduate School of Energy and Environment, King Mongkut's University of Technology \\ Thonburi, 126 Prachauthit Rd., Bangmod, Tungkru, Bangkok 10140, Thailand \\ ${ }^{2}$ Center of Excellence on Energy Technology and Environment (CEE), PERDO, Ministry of Higher \\ Education, Science, Research and Innovation, Bangkok, Thailand
}

\begin{abstract}
Increasing population and affluence have had a direct influence on increasing the energy demand of nations across the globe. Energy from non-renewable fossil resources has associated emissions of greenhouse gases contributing to climate change, a major challenge facing us today. The governments of many countries have tried to address the twin issues of limited local availability of fossil resources and greenhouse gas emissions by promoting the use of bioenergy. Bioenergy is not automatically sustainable unlike popular belief. Assessing its sustainability using a life cycle thinking approach reveals many caveats, not only regarding greenhouse gas emissions but also other environmental impacts that are often ignored. The environmental assessment of palm oil-based biodiesel shows the trade-offs when considering all the life cycle stages of the biofuel supply chain and also when multiple impact categories are considered. The so-called carbon neutrality becomes questionable and other impacts from agriculture arising due to the use of land and agrochemicals are also seen to be very significant. Ignoring these in policymaking could result in serious unintended consequences. Thus, the importance of life cycle thinking in sustainability assessment is illustrated. This will be critical in addressing national needs while also moving towards the United Nations' Sustainable Development Goals.
\end{abstract}

\section{Introduction}

Energy is one of the most basic human needs along with food and shelter. It is required, directly or indirectly, for all human activities, especially those for procuring food and shelter. In fact, as societies develop and become more affluent, their energy consumption is also seen to increase. More affluent societies have been seen to shift to a more meat-based diet requiring more agriculture to support the livestock [1]. This leads to a higher energy demand along with other environmental pressures including stress on natural resources such as land and water, and pollution from emissions to air, water, and soil. Increased comfort for shelter in more affluent societies leads to higher energy demand, especially from lighting, heating, and air conditioning requirements.

\footnotetext{
* Corresponding author: shabbir.ghe@kmutt.ac.th; shabbirg@ hotmail.com
} 
The source of all energy on the planet can somehow be traced back to the sun; however, human activities often rely on fossil resources which are energy-dense and available with relatively less effort. Fossil resources such as coal, oil, and natural gas, are considered nonrenewable because it has taken millions of years to produce them but they are being consumed in very large quantities in a very short period of time (order of decades or centuries) making their rate of consumption far in excess of their rate of production. The other issue with the use of fossil resources is that they are carbon-based; their combustion for energy purposes results in the emission of carbon dioxide and many other gases such as sulphur dioxide, nitrogen oxides, fine particulate matter, and so on. Carbon dioxide is a greenhouse gas linked to the increase of global temperatures which leads to changes in climate that has serious effects on our very existence. The other emissions such as sulphur dioxide and nitrogen oxides have other effects on the environment such as acidification, eutrophication, etc. Fine particulate matter has serious effects on human health.

As we cannot do without energy but need to avoid the negative effects described above, alternative sources of energy are needed. Energy from biomass or bioenergy, is one such possible source of energy. As biomass can be grown via agriculture in a relatively short period of time (order of years) as compared to fossil resources (order of millions of years), it is considered relatively renewable. Also, as the carbon in the biomass comes from the atmosphere during photosynthesis, the carbon dioxide released when combusting the biomass for energy could be considered not to pump additional carbon dioxide into the atmosphere. It must be noted here that even fossil resources have been created from biomass in the past; however, the carbon locked in that has been out of the carbon cycle of the earth for millennia. Introducing that back very quickly as carbon dioxide into the atmosphere disturbs the current carbon cycle leading to the devastating effects associated with climate change. Thus, bioenergy seems to be a relatively benign energy source that is renewable and does not result in additional carbon dioxide in the atmosphere.

However, the issue is more complicated than may be apparent at first instance. Growing the biomass requires fertilizers, other agrochemicals, land, and water, all of which have associated emissions of greenhouse gases (carbon dioxide as well as others such as methane and nitrous oxide). Processing the biomass to more convenient forms of energy, for example as liquid transportation fuels to replace fossil oil-based fuels, has additional demands on resources and results in further greenhouse gas emissions. In addition to these "life cycle" greenhouse gas emissions, there can be substantial emissions even before the cultivation of biomass begins, if high carbon stock land such as forests is cleared for agriculture. Going even further, even if other agricultural land is converted to crops for bioenergy production, there can be greenhouse gas emissions from the cultivation of the crop that has been displaced by the bioenergy crop, should it be planted on high carbon stock land. So the expanding life cycle of bioenergy makes it very difficult to retain the socalled "carbon neutrality" often associated with bioenergy. And then again, agriculture requires the use of limited resources such as land and water, and results in emissions of acidifying, eutrophying, and toxic substances into the environment which have their own associated problems [2,3].

Thus, the sustainability assessment of bioenergy requires a broadening of the study scope beyond fossil energy resources and greenhouse gas emissions as well as beyond only the use of the energy carrier for energy. The inclusion of all life cycle stages and multiple impact categories can have a significant effect on the results, which if not considered, can make the decision to adopt bioenergy have huge unintended consequences. This article will illustrate these aspects of the importance of life cycle thinking in sustainability assessment using the example of biodiesel derived from palm oil. 


\section{Palm oil-based biodiesel}

Energy carriers produced from biomass can be in solid (e.g., pellets), liquid (e.g., biofuels), or gaseous (e.g., biogas) forms. For the purpose of illustration, this paper considers the example of biodiesel produced from palm oil (hereafter referred to as only "biodiesel"). Biodiesel can replace fossil diesel in automobiles without the need for significant change in engine (up to a certain percentage blend with diesel) or a change in infrastructure (since it a liquid transportation fuel with properties very similar to fossil diesel). It is produced by the transesterification reaction of palm oil with alcohol (methanol or ethanol). The carbon in the biodiesel comes from the palm fruit which in turn was absorbed from the atmosphere as carbon dioxide during the growth of the oil palm tree. Hence, the release of carbon dioxide from the combustion of biodiesel does not input additional carbon dioxide to the atmosphere. However, there are other greenhouse gas emissions throughout the life cycle of biodiesel; the life cycle of biodiesel is illustrated in Fig. 1. The cultivation of oil palm requires fertilizers, the production and use of which can have substantial greenhouse gas emissions. The use of energy and the wastewater produced at the palm oil mill is another source of greenhouse gas emissions as is the production of alcohol for the biodiesel production (transesterification). Change of land use from forest or other uses to oil palm cultivation has also associated greenhouse gas emissions. The greenhouse gas emissions from the intermediate transportation between the processes (e.g., transport of fresh fruit bunches from the oil palm plantation to the palm oil mill) must also be included.

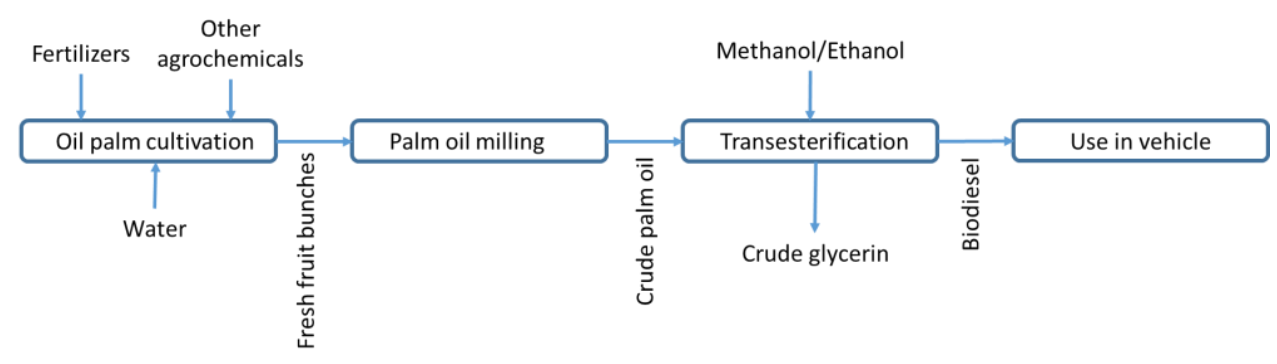

Fig. 1. Simplified life cycle of palm oil biodiesel production and use

\section{Life cycle greenhouse gas emissions from biodiesel}

Biodiesel is produced by the transesterification reaction between vegetable oil, palm oil in this example, and alcohol (methanol or ethanol). As the carbon in the palm oil is of biogenic origin, the carbon dioxide produced by its combustion can be considered not to add to atmospheric carbon dioxide as explained before. However, the methanol (or ethanol) is often of fossil origin and the carbon dioxide released from the carbon component of methanol in the biodiesel still needs to be accounted for. That, however, is not a very big contributor to carbon dioxide emissions from the biodiesel life cycle. The production cycle of biodiesel (shown in Fig. 1) has other sources of greenhouse gas emissions as explained above, some of the major ones being the fertilizer production and use (especially $\mathrm{N}$ fertilizers), and methane emissions from the palm oil mill effluent (wastewater). There are substantial greenhouse gas emissions if forest land is converted to oil palm plantations.

The life cycle greenhouse gas emission from the production and use of biodiesel are presented in Fig. 2 [4]. The values are shown as a range because there can be significant variation in greenhouse gas emissions depending on the practices followed at the various life cycle stages. The lowest values in the range are when the empty fruit bunches (the 
remains after palm oil is extracted from the fresh fruit bunches) are utilized for cocomposting with the palm oil mill effluent and the latter is itself treated anaerobically and the biogas produced is captured and utilized for energy. The highest values in the range are for the case when neither the empty fruit bunches nor the biogas from the palm oil mill are utilized. The benchmark to compare the life cycle greenhouse gas emissions of biodiesel is that of the fossil diesel it should replace which is $85 \mathrm{gCO}_{2} \mathrm{eq} / \mathrm{MJ}$. It can be seen that for most of the cases, the life cycle greenhouse gas emissions of biodiesel are lower than that of diesel, except for the case when forest land is transformed into oil palm plantations. This gives a powerful message to avoid the conversion of pristine forests or other land with high carbon stock into agriculture. Also, the utilization of biomass residues and wastes can have a significant effect on the reduction of the greenhouse gas emissions from the biodiesel life cycle.

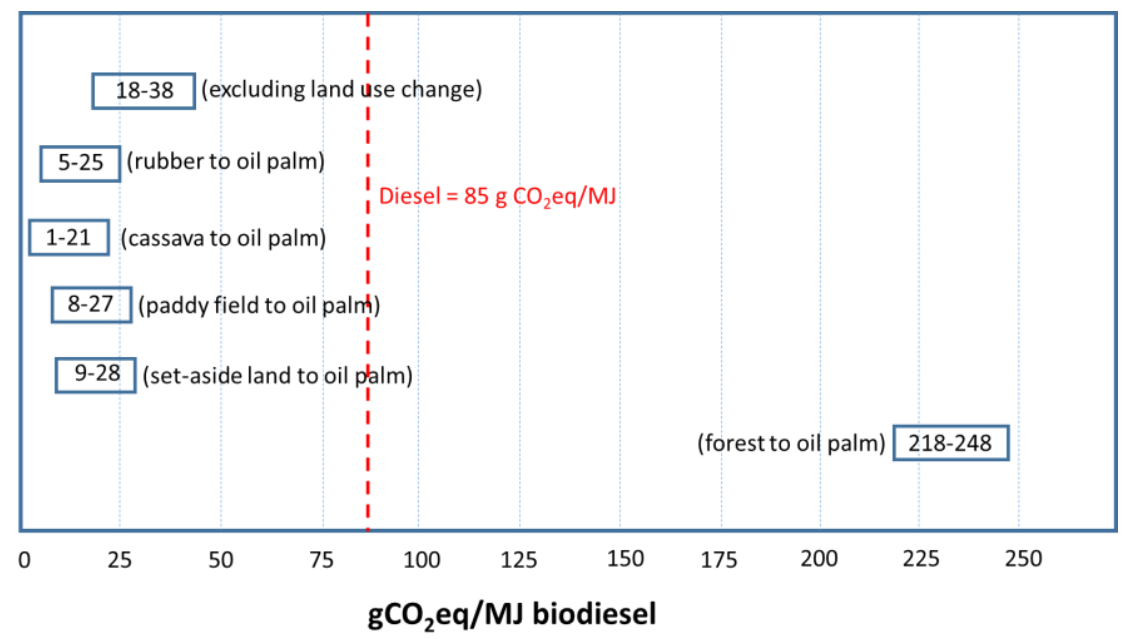

Fig. 2. Life cycle greenhouse gas emissions from biodiesel production and use

\section{Life cycle assessment of biodiesel}

The previous section illustrated the advantage of looking at the entire life cycle of biodiesel. However, only greenhouse gas emissions were considered in the analysis. Except for the case when forest land was transformed to oil palm plantations, biodiesel performed better than diesel. Now, just as we expanded the scope of the study to look at the entire life cycle of biodiesel, expanding the scope further to include other impacts would also have very important implications on decision making. As mentioned in the introduction, the most attractive feature for the promotion of bioenergy has been the use of renewable resources (biomass) and a reduction in climate change-inducing greenhouse gas emissions. These two aspects, energy resources and greenhouse gas emissions, are often used in policy making at the government level. Even when these two aspects are considered (Fig. 3) instead of only greenhouse gas emissions alone, biodiesel is clearly much better than diesel apparently vindicating the promotion of biofuels [5].

However, there are many other impacts that may also need to be considered which may have a significant impact on the decision making. A full life cycle assessment considering a range of impact categories should be considered to make the comparative evaluation. Using the Thai Eco Scarcity method, which is distance-to-target method of life cycle impact assessment based on Thai policy targets, a study was conducted to evaluate the environmental profile of biodiesel as compared to diesel [6]. Employing this method gives 
the environmental impacts in units of Thai Eco Points where a larger value indicates higher environmental burdens. The results are shown in Fig. 4; now the diesel becomes better than biodiesel even though the latter performs better in terms of greenhouse gas emissions and energy resources [5]. Oil palm cultivation requires the use of land, an important natural resource. The use of pesticides also has significant environmental impacts (toxicity) as does fertilizer use especially in terms of nutrients released to freshwater (eutrophication). The combined effect of all these make the choice of biodiesel over diesel questionable. This important insight is missed when considering a comparison based only on greenhouse gas emissions or along with energy resources.

This is not to conclude that biodiesel should not be promoted, but care has to be taken to check the effect of all impacts. Efforts have to be made towards improving the agricultural practices for increasing yield, reducing the use of resources (land, water, agrochemicals, etc.), and efficiently utilizing byproducts at every stage of the life cycle so that the environmental profile of the biodiesel can actually be better than diesel from a life cycle perspective.

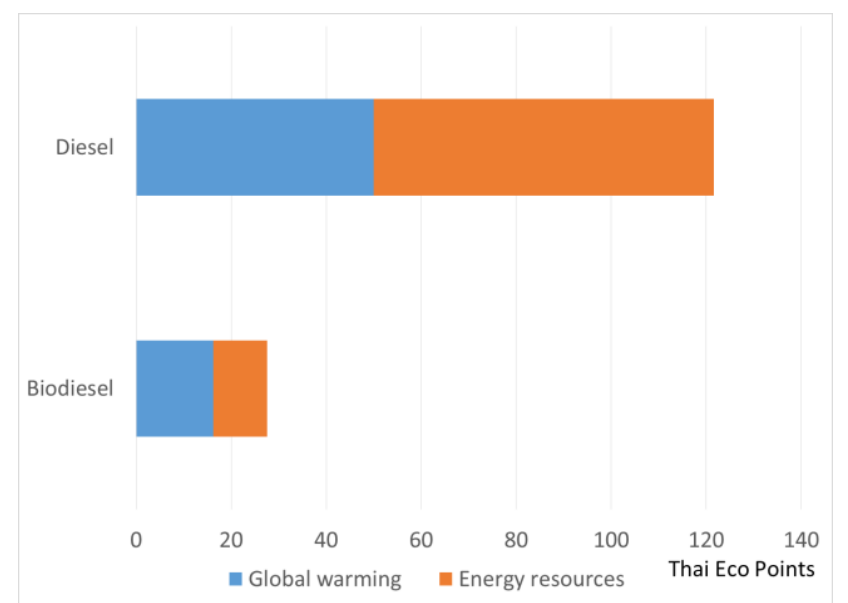

Fig. 3. Global warming (greenhouse gas emissions) and energy resources for biodiesel and diesel

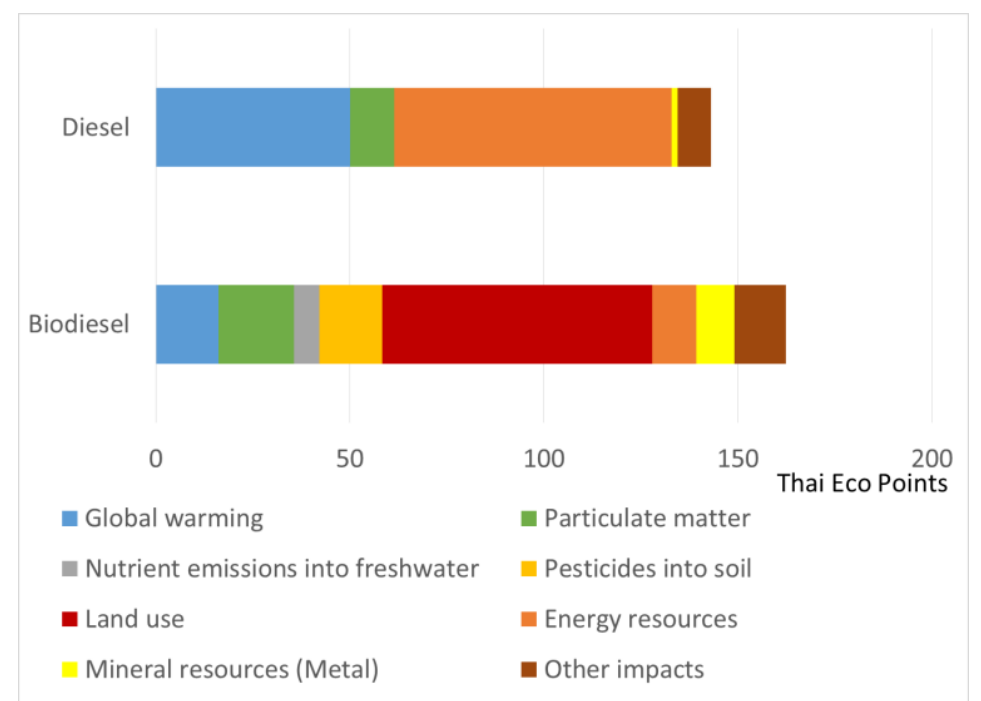

Fig. 4. Life cycle assessment results for biodiesel and diesel 


\section{Life cycle sustainability assessment}

In the previous sections, we have applied life cycle thinking only to the environmental dimension of sustainability; however the economic and social dimensions also need to be considered to make a complete evaluation (Fig. 5). Life cycle-based tools such as life cycle costing and social life cycle assessment are available which can complement (environmental) life cycle assessment that was considered in the previous section. There other approaches and indicators provided inter alia by the Global Bioenergy Partnership (GBEP) or the Bioenergy and Food Security Analytical Framework (BEFS-AF) from the Food and Agriculture Organization of the United Nations, that could also be used for a full sustainability assessment [2]. The important point is that just as problem shifting between life cycle stages (Section 3) and between environmental impact categories (Section 4) can be avoided by life cycle thinking, extending that principle for sustainability assessment requires the consideration of all three dimensions of sustainability to avoid problem shifting between the dimensions.

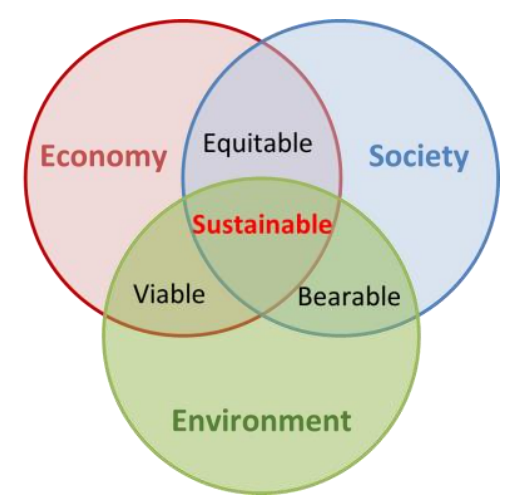

Fig. 5. Dimensions of sustainability

\section{Concluding remarks}

The application and importance of life cycle thinking was demonstrated for the sustainability assessment of bioenergy system. Taking the example of palm oil-based biodiesel, it was seen that looking at the entire life cycle even for only greenhouse gas emissions alone gave interesting results which were quite different from considering just the use of biodiesel in vehicles. The life cycle greenhouse gas emission results showed the processes and life cycle stages with high emissions which was important to reveal the conditions for ensuring the benefit of biodiesel as compared to diesel. However, adding several other impact categories completely overturned the comparative results indicating the danger of making policy decisions solely on the basis of greenhouse gas emissions or even with the consideration of energy resources. The life cycle assessment results showed several impacts particularly related to agriculture that would be need to be managed to improve the environmental profile of the biodiesel over and above diesel. The idea of life cycle thinking needs to be further broadened in scope to include all three dimensions of sustainability to ensure that one dimension is not improved at the expense of the other two; rather all dimensions need to be improved. The idea of life cycle thinking is directly or indirectly embedded in several of the United Nation's Sustainable Development Goals 
(SDGs). The most direct application is in SDG12: Responsible Consumption and Production. For the case of bioenergy, the most direct link is with SDG7: Affordable and Clean Energy and SDG13: Climate Action. These are in turn linked to SDG1: No Poverty (especially energy poverty), SDG14: Life Below Water, and SDG15: Life on Land.

This article is based on a keynote presentation by the author at the International Conference on Environmental and Energy Sustainabilities (ICEES 2021), Seoul, Republic of Korea. The author would like to thank the organizers of the conference, particularly Dr Ahmad Harakan for the invitation to the conference and the opportunity to write this paper.

\section{References}

1. IPCC, Summary for Policymakers (Intergovernmental Panel on Climate Change, 2019)

2. S. . Gheewala, N. Kittner, and X. Shi, in Routledge Handb. Energy Asia (Taylor and Francis, 2018), p. 14

3. S. H. Gheewala, B. Damen, and X. Shi, WIREs Clim. Chang. 4, 497 (2013)

4. T. Silalertruksa and S. H. Gheewala, J. Ind. Ecol. 16, 541 (2012)

5. N. Lecksiwilai and S. H. Gheewala, Sustain. Prod. Consum. 22, 177 (2020)

6. N. Lecksiwilai and S. H. Gheewala, Environ. Sci. Policy 94, 82 (2019) 